\title{
Variação anual da composição bromatológica de duas forrageiras cultivadas nas baixadas litorâneas do Estado do Rio de Janeiro ${ }^{1}$, Brasil
}

\author{
Variation on the annual nutritive value of two grasses cropped in the litoral lowlands of the \\ State of Rio de Janeiro, Brazil
}

\author{
Paulo Drude de Lacerda ${ }^{2}$ Pedro Malafaia ${ }^{3}$ Ricardo Augusto Mendonça Vieira ${ }^{4}$ \\ Douglas Sampaio Henrique ${ }^{5}$ Ivone Elizabeth Van Der Made ${ }^{5}$ Ana Raquel Gomes Faria
}

\section{RESUMO}

Análises de matéria seca (MS), proteína bruta $(P B)$, fibra em detergente neutro $(F D N)$, lignina $(L I G)$, frações de carboidratos e de compostos nitrogenados foram realizadas em capins provenientes de três propriedades rurais da região das baixadas litorâneas do Estado do Rio de Janeiro. Amostras do capim hemártria (HEM) (Hemarthria altissima) $e$ do capim elefante (Pennisetum purpureum), utilizado como capineira (CEC) e sob pastejo rotacionado (CEP) foram coletadas mensalmente, ao longo das estações do ano agrícola de 1997 e 1998. Foram observados efeitos da estação do ano sobre a forrageira e entre forrageiras dentro de uma estação do ano. A quantidade de PB variou de 37,2 $\mathrm{g} \mathrm{kg-1}$ de $M S$ no CEC a 131,5g kg-1 de MS no CEP. O capim hemártria apresentou valores de $P B$ que variaram de 69,8g $\mathrm{kg}-1$ de $\mathrm{MS}$ no verão à 99,7g $\mathrm{kg}-1$ de MS no inverno. A quantidade de FDN variou de 702,9 até 811,6 $\mathrm{g} \mathrm{kg-1}$ de MS ao longo do ano; os valores mais baixos foram verificados no CEP. Os valores de lignina no CEC foram os maiores entre os capins (55,3 a 81,3g kg-1 de MS). A fração de carboidratos não estruturais variou de 20,9 a 85,5g $\mathrm{kg}-1$ de MS. A quantidade de FDNcp variou de 673,6 até 794,5g kg-1 de MS. O capim hemártria teve os maiores valores da fração $B 2$ e os menores valores da fração $C$ de carboidratos durante todo o ano. Os valores da fração $C$ de carboidratos variaram de 126,2 a 135,3g kg-1 de MS para o CEP, 149,2 a 177,7g kg-1 de MS para o CEC e 84,0 a 107,8g kg-1 de MS para o capim hemártria. As frações nitrogenadas $A, B 1, B 2, B 3$ e $C$ tiveram valores entre 9,8 e 36,4;0,73 e 12,6; 11,1 e 44,1; 2,2 e 34,5 e 6,7 e 12,8g kg-1 de $\mathrm{MS}$, respectivamente.

Palavras-chave: capim elefante, capim hemártria, frações de carboidratos, frações nitrogenadas.

\section{ABSTRACT}

Chemical analyses of grasses from three farms located in the coastal lowland region of Rio de Janeiro were made. Elephant-grass (Pennisetum purpureum) used as chopped fresh forage and in rotational grazing, and the limpo-grass (Hemarthria altissima), were sampled monthly. The values of dry matter (DM), crude protein (CP), neutral detergent fiber (NDF), lignin (LIG) and the carbohydrate and nitrogen fractions were compared throughout the year. There were effects of the season on the grass and between grasses in a season of the year. Crude protein ranged from $37,2 \mathrm{~g} \mathrm{~kg}-1$ of DM in the elephant-grass from the daily cut forage system to $131,5 \mathrm{~g} \mathrm{~kg}-1$ of DM in the rotational grazing system. The limpo-grass showed values that ranged from $69,8 g$ $\mathrm{kg}-1$ of DM to $99,7 \mathrm{~g} \mathrm{kg-1}$ of DM. The values of NDF varied between 702,9 and 811,6g kg-1 of DM through the year, and the lowest means were obtained from the rotational grazing system of the elephant-grass. The daily chopped elephant-grass gave the highest values of lignin (55,3 to 81,3g kg-1 of DM ). The non fibrous carbohydrate fraction $(A+B 1)$ ranged from 20,9 to $85,5 \mathrm{~g} \mathrm{~kg}-1$ of $\mathrm{DM}$. The fibrous fraction, containing fractions B2 and $C$, presented means between 673,6 and $794,5 \mathrm{~g} \mathrm{kg-1}$ of DM. The limpo-grass showed the highest values of the B2 fraction, and the lowest values of fraction $C$, during the year. The values of fraction $C$ of elephant-grass from the two systems of exploration ranged between 126,1 and $135,3 \mathrm{~g}$ $\mathrm{kg}-1$ of DM, and 149,2 and 177,7 $\mathrm{gg}-1$ of DM, while the limpo-grass ranged from 84,0 to $107,8 \mathrm{~g} \mathrm{kg-1}$ of DM. The nitrogen fractions varied between seasons and between species and types of exploration. Fractions ranged from 9,8 to $36,4 \mathrm{~g}$ kg-1 DM (A), 0,73 to $12,6 \mathrm{~g} \mathrm{kg-1} \mathrm{of} \mathrm{DM} \mathrm{(B1),} \mathrm{11,1} \mathrm{to} 44,1 \mathrm{~g} \mathrm{kg-1} \mathrm{of}$ $D M$ (B2), 2,2 to $34,5 \mathrm{~g} \mathrm{kg-1}$ of DM (B3) and from 6,7 to $12,8 \mathrm{~g}$ kg-1 of $D M(C)$.

\footnotetext{
${ }^{1}$ Parte da Dissertação de Mestrado apresentada pelo primeiro autor no Programa de Pós-graduação em Zootecnia (PPGZ), Universidade Federal Rural do Rio de Janeiro (UFRRJ). Projeto de pesquisa financiado pela FAPERJ.

${ }_{3}^{2}$ Zootecnista, MSc, EMATER-RJ, 28990-000, Saquarema, RJ.

${ }^{3}$ Zootecnista, Doutor, Professor Adjunto, UFRRJ-IZ-DNAP, 23851-970, Seropédica, RJ. E- mail: malafaia1 @ig.com.br. Autor para correspondência.

${ }^{4}$ Zootecnista, Doutor, Professor Adjunto, UENF-CCTA, 28015-620, Campos dos Goytacases, RJ.

${ }^{5}$ Estudante de Mestrado, PPGZ, UFRRJ.
} 
Key words: elephant-grass, limpo-grass, nitrogen and carbohydrate fractions.

\section{INTRODUÇÃO}

$\mathrm{Na}$ região das baixadas litorâneas do Estado do Rio de Janeiro, cerca de $60 \%$ da produção leiteira é proveniente de propriedades com produção inferior a $200 \mathrm{~L} \mathrm{d-1.} \mathrm{Nestas,} \mathrm{a} \mathrm{utilização} \mathrm{de} \mathrm{pastos} \mathrm{e}$ capineiras constitui uma prática dominante. O capim elefante (Pennisetum purpureum) encontra-se disseminado na quase totalidade das propriedades leiteiras da região, ocupando áreas de corte (capineiras) e, em menor escala, é utilizado também para pastejo. A composição química das diversas variedades desta gramínea apresenta variações decorrentes de fatores como idade e altura da planta (ANDRADE \& GOMIDE, 1972), fertilidade (ANDRADE et al., 1995) e variação estacional (PEDREIRA, 1976).

Após avaliarem oito acessos de hemártria (Hemarthria altissima), GHISI et al. (1995) concluíram que a espécie possui boa aceitabilidade, notadamente nos períodos de seca. A proteína bruta variou de 62,1 a 98,1g kg-1 de MS, sendo os maiores valores encontrados na estação da seca (GHISI et al., 1995). Valores médios de $90 \mathrm{~g}$ de proteína bruta $\mathrm{kg}-1$ de MS foram determinados em sete acessos de hemártria, avaliados no período seco do ano; durante o período chuvoso, houve uma diminuição nos valores de proteína bruta, que caíram para cerca de $70 \mathrm{~g} \mathrm{~kg}-1$ de MS, em virtude do maior crescimento vegetativo das plantas neste período e do aumento na fração colmo, que possui teor protéico inferior ao da fração lâmina (CARVALHO et al., 1996).

Os carboidratos são importantes na nutrição de ruminantes, pois representam a principal fonte de energia para os microrganismos ruminais e para o animal (MERTENS, 1996). Nos ruminantes criados extensivamente, praticamente 70 a $90 \%$ dos carboidratos consumidos são oriundos dos constituintes da parede celular vegetal. MALAFAIA et al. (1998) relataram para o capim elefante valores de 48,5; 342,5; e 101,9g kg-1 de MS para as frações CNE, B2 e C, respectivamente. CABRAL et al. (2000a) determinaram as frações relativas aos carboidratos do capim elefante com 42 e 63 dias de idade nas estações da primavera e verão; os resultados médios variaram de 50,5 a 50,3g kg-1 de MS para a fração CNE; 517,1 a $531,6 \mathrm{~g} \mathrm{~kg}-1$ de MS para a fração B2 e 186,2 a 204,4g kg-1 de MS para a fração $\mathrm{C}$, nas duas idades de corte, respectivamente.

Este trabalho teve como objetivo determinar a composição bromatológica, durante as estações do ano, em duas forrageiras procedentes da região das baixadas litorâneas do Estado do Rio de Janeiro.

\section{MATERIAL E MÉTODOS}

As forrageiras foram provenientes de três propriedades rurais, situadas nos municípios de Araruama e Saquarema, com menos de 50 ha e com produção média de 200 Litros d-1. As amostras das forrageiras foram coletadas mensalmente, entre os dias 15 e 18, a partir de outubro de 1997 até outubro de 1998. Em cada estação do ano, foram realizadas três coletas para cada forrageira, sendo as amostras obtidas em duplicata. Dessa forma, cada forrageira deu origem a seis amostras em cada estação do ano.

Na primeira propriedade, o capim hemártria (HEM) era utilizado para pastejo contínuo e pastejo diferido. De outubro de 97 a abril de 98, a área foi utilizada com $675 \mathrm{kgPV}$ ha-1, em pastejo contínuo. De maio de 98 a outubro de 98 , foi coletado material após um descanso médio de 25 dias, realizado a cada pastejo por seis dias com 450kgPV ha-1. As amostras, obtidas por intermédio de cortes manuais, eram colhidas na altura da parte removida pelos animais.

Na segunda propriedade, o capim elefante (cv. Cameroon) era manejado sob pastejo rotacionado (CEP). De outubro de 97 a março de 98, foi utilizado em pastejo por 5 a 6 horas por dia e um descanso médio de 35 dias. A adubação com uréia (40kg ha-1 de N) foi feita em dezembro de 98 . De abril de 98 a outubro de 98, a área foi utilizada em pastejo por duas a três horas por dia e descansando por 35 dias. A partir de março de 98, foi realizada uma fertirrigação (aplicação de esterco diluído em água) nos piquetes. As amostras também foram obtidas por intermédio de cortes manuais realizados na altura do pastejo feito pelos animais.

$\mathrm{Na}$ terceira propriedade, o capim elefante era utilizado sob capineira (CEC) para corte diário. De outubro de 97 a outubro de 98 , a coleta das amostras era realizada no material oferecido aos animais, após a desintegração na picadeira. Os cortes eram realizados quando as plantas tinham aproximadamente $1,8 \mathrm{~m}$ de altura.

As forrageiras coletadas eram acondicionadas em sacos plásticos hermeticamente fechados, transportadas sob refrigeração até o laboratório, onde eram pesadas, pré-secas, moídas para atingirem a granulometria de três mm e armazenadas em recipientes apropriados. As análises de matéria seca (MS), proteína bruta (PB), extrato etéreo (EE) e matéria mineral (MM) foram realizadas seguindo procedimentos da AOAC (1990). As determinações da fibra em detergente neutro (FDN) 
e lignina foram feitas pela técnica proposta por VAN SOEST et al., (1991).

A fração de carboidratos não estruturais (CNE) foi obtida pela diferença entre o teor de carboidratos totais (CHT) e o teor de fibra em detergente neutro corrigida para cinzas e proteínas (FDNcp). A fração C foi obtida pela incubação da FDN por 96 horas em líquido ruminal e a fração B2 calculada pela diferença FDNcp - C (CABRAL et al., 2000a). A fração nitrogenada A foi obtida após o tratamento de $0,50 \mathrm{~g}$ da amostra com o ácido tricloro acético (TCA $100 \mathrm{~g} \mathrm{~L}-1)$ por 30 minutos (MALAFAIA \& VIEIRA, 1997). A determinação do nitrogênio solúvel total foi realizada incubando-se a amostra $(0,5 \mathrm{~g})$ com $50 \mathrm{~mL}$ do tampão borato-fosfato (TBF). Após três horas de incubação, a amostra residual foi filtrada em papel de filtro e feita a análise do nitrogênio residual insolúvel no TBF. O nitrogênio solúvel total foi obtido pela diferença entre o teor de nitrogênio total e o teor do nitrogênio insolúvel no TBF (MALAFAIA \& VIEIRA, 1997). A fração pertinente às proteinas solúveis (B1) foi determinada pela diferença entre a fração nitrogênio solúvel total e a fração A. Da diferença entre o teor de nitrogênio insolúvel em detergente neutro e o teor de nitrogênio insolúvel em detergente ácido, pode-se estimar a fração B3. A fração $\mathrm{C}$ foi determinada pelo nitrogênio insolúvel em detergente ácido (MALAFAIA \& VIEIRA, 1997). A fração B2 foi obtida pela diferença entre o teor de nitrogênio insolúvel no tampão boratofosfato e o teor de nitrogênio insolúvel em detergente neutro.

Os parâmetros estudados foram analisados por intermédio da análise de variância e pela utilização do teste "t", assumindo-se o nível de 5\% de probabilidade de erro para a comparação das médias.

\section{RESULTADOS E DISCUSSÃO}

Foram observados efeitos da estação sobre a forrageira (Tabela 1), bem como entre forrageiras dentro de uma estação do ano (Tabela 2). Excetuandose a média dos meses de primavera, os valores de proteína bruta do capim elefante manejado como capineira estiveram sempre abaixo do mínimo necessário para a mantença de um bovino adulto (Tabela 1), cuja exigência se situa em torno de 60 a $70 \mathrm{~g}$ kg-1 de MS (MILFORD \& MINSON, 1966). Em todas as estações, os teores de proteína bruta do capim elefante manejado como capineira foram menores do que os encontrados para os outros capins (Tabela 2). Os valores de FDN foram menores na estação da primavera para o capim elefante manejado como

Tabela 1 - Quantidades de matéria seca (MS), proteína bruta (PB), fibra em detergente neutro (FDN), fibra em detergente neutro corrigida para cinzas e proteínas (FDNcp), carboidratos totais (CHT), lignina (Lig), carboidratos não estruturais (CNE), frações $\mathrm{B}_{2}$ e $\mathrm{C}$ de carboidratos e frações $\mathrm{A}, \mathrm{B}_{1}, \mathrm{~B}_{2}, \mathrm{~B}_{3}$ e $\mathrm{C}$ de compostos nitrogenados das gramíneas ao longo das estações do ano.

\begin{tabular}{|c|c|c|c|c|c|c|c|c|c|c|c|c|c|c|}
\hline \multirow[b]{2}{*}{ Amostra } & \multirow[b]{2}{*}{$\mathrm{MS}^{1}$} & \multirow[b]{2}{*}{$\mathrm{PB}^{2}$} & \multirow[b]{2}{*}{$\mathrm{FDN}^{2}$} & \multirow[b]{2}{*}{ FDNcp $^{2}$} & \multirow[b]{2}{*}{$\mathrm{CHT}^{2}$} & \multirow[b]{2}{*}{ Lig. $^{2}$} & \multicolumn{3}{|c|}{ Frações de CHT } & \multicolumn{5}{|c|}{ Frações nitrogenadas } \\
\hline & & & & & & & $\mathrm{CNE}^{2}$ & $\mathrm{~B}_{2}^{2}$ & $C^{2}$ & $\mathrm{~A}^{2}$ & $\mathrm{~B}_{1}^{2}$ & $\mathrm{~B}_{2}^{2}$ & $\mathrm{~B}_{3}^{2}$ & $\mathrm{C}^{2}$ \\
\hline \multicolumn{15}{|c|}{ Capim elefante - Capineira } \\
\hline Primavera & $181,2^{\mathrm{c}}$ & $73,9^{\mathrm{a}}$ & $756,2^{b}$ & $720,3^{\mathrm{b}}$ & $800,8^{\mathrm{b}}$ & $55,3^{\mathrm{b}}$ & $80,6^{\mathrm{a}}$ & $571,1^{\mathrm{b}}$ & $149,2^{\mathrm{b}}$ & $22,6^{\mathrm{a}}$ & $2,6^{\mathrm{bc}}$ & $25,7^{\mathrm{a}}$ & $10,3^{\mathrm{a}}$ & $12,7^{\mathrm{a}}$ \\
\hline Verão & $240,9^{b}$ & $38,2^{\mathrm{bc}}$ & $811,6^{\mathrm{a}}$ & $794,5^{\mathrm{a}}$ & $865,1^{\mathrm{a}}$ & $61,2^{\mathrm{b}}$ & $70,6^{\mathrm{a}}$ & $633,0^{\mathrm{a}}$ & $161,5^{\mathrm{ab}}$ & $9,8^{\mathrm{b}}$ & $2,2^{\mathrm{c}}$ & $13,9^{\mathrm{b}}$ & $2,5^{\mathrm{b}}$ & $9,8^{\mathrm{b}}$ \\
\hline Outono & $280,4^{\mathrm{a}}$ & $37,2^{\mathrm{c}}$ & $792,9^{\mathrm{a}}$ & $780,4^{\mathrm{a}}$ & $865,9^{\mathrm{a}}$ & $81,3^{\mathrm{a}}$ & $85,5^{\mathrm{a}}$ & $612,1^{\mathrm{a}}$ & $168,3^{\mathrm{ab}}$ & $10,6^{\mathrm{b}}$ & $4,1^{b}$ & $11,1^{\mathrm{b}}$ & $2,2^{\mathrm{b}}$ & $9,1^{\mathrm{b}}$ \\
\hline Inverno & $253,7^{\mathrm{ab}}$ & $57,2^{\mathrm{ab}}$ & $797,9^{b}$ & $779,8^{\mathrm{a}}$ & $814,4^{b}$ & $66,6^{\mathrm{ab}}$ & $34,7^{\mathrm{c}}$ & $602,1^{\text {ab }}$ & $177,7^{\mathrm{a}}$ & $18,2^{\mathrm{a}}$ & $8,3^{\mathrm{a}}$ & $13,6^{\mathrm{b}}$ & $5,3^{\mathrm{b}}$ & $11,8^{\mathrm{a}}$ \\
\hline \multicolumn{15}{|c|}{ Capim Hemártria } \\
\hline Primavera & $207,3^{\mathrm{c}}$ & $94,3^{\mathrm{a}}$ & $775,5^{\mathrm{a}}$ & $743,7^{\mathrm{b}}$ & $791,2^{\mathrm{c}}$ & $50,4^{\mathrm{a}}$ & $47,5^{\mathrm{ab}}$ & $635,9^{\mathrm{b}}$ & $107,8^{\mathrm{a}}$ & $31,1^{\mathrm{a}}$ & $0,73^{\mathrm{c}}$ & $26,2^{\mathrm{a}}$ & $23,5^{\mathrm{b}}$ & $12,8^{\mathrm{a}}$ \\
\hline Verão & $248,6^{\mathrm{b}}$ & $69,8^{\mathrm{b}}$ & $788,9^{\mathrm{a}}$ & $775,4^{\mathrm{a}}$ & $839,7^{\mathrm{a}}$ & $44,8^{\mathrm{a}}$ & $64,3^{a}$ & $678,2^{\mathrm{a}}$ & $97,2^{\mathrm{a}}$ & $21,2^{\mathrm{b}}$ & $1,51^{\mathrm{b}}$ & $20,5^{\mathrm{a}}$ & $14,2^{\mathrm{c}}$ & $12,4^{\mathrm{a}}$ \\
\hline Outono & $262,0^{\mathrm{a}}$ & $73,2^{\mathrm{b}}$ & $796,4^{\mathrm{a}}$ & $772,9^{\mathrm{a}}$ & $814,9^{b}$ & $56,2^{\mathrm{a}}$ & $41,9^{\mathrm{bc}}$ & $688,9^{\mathrm{a}}$ & $84,0^{\mathrm{b}}$ & $21,6^{\mathrm{b}}$ & $2,2^{\mathrm{a}}$ & $21,7^{\mathrm{a}}$ & $16,8^{\mathrm{c}}$ & $10,9^{\mathrm{b}}$ \\
\hline Inverno & $230,6^{\mathrm{b}}$ & $99,7^{\mathrm{a}}$ & $789,6^{\mathrm{a}}$ & $762,5^{\mathrm{ab}}$ & $788,8^{\mathrm{c}}$ & $48,6^{\mathrm{a}}$ & $26,4^{\mathrm{c}}$ & $663,4^{\mathrm{ab}}$ & $99,1^{\mathrm{a}}$ & $31,7^{\mathrm{a}}$ & $2,4^{\mathrm{a}}$ & $23,8^{\mathrm{a}}$ & $30,4^{\mathrm{a}}$ & $11,3^{\mathrm{a}}$ \\
\hline \multicolumn{15}{|c|}{ Capim elefante - Pastejo } \\
\hline Primavera & $253,6^{\mathrm{b}}$ & $92,8^{\mathrm{b}}$ & $726,1^{\mathrm{ab}}$ & $698,1^{\mathrm{ab}}$ & $766,0^{\mathrm{a}}$ & $36,8^{\mathrm{a}}$ & $67,9^{\mathrm{a}}$ & $565,5^{\mathrm{ab}}$ & $132,6^{\mathrm{a}}$ & $27,1^{\mathrm{b}}$ & $5,6^{\mathrm{b}}$ & $30,5^{b}$ & $19,3^{\mathrm{c}}$ & $10,2^{a b}$ \\
\hline Verão & $282,0^{\mathrm{a}}$ & $117,0^{\mathrm{a}}$ & $746,6^{\mathrm{a}}$ & $721,0^{\mathrm{a}}$ & $741,9^{b}$ & $42,5^{\mathrm{a}}$ & $20,9^{c}$ & $589,1^{\mathrm{a}}$ & $131,9^{\mathrm{a}}$ & $34,0^{\mathrm{a}}$ & $4,6^{\mathrm{b}}$ & $40,4^{\mathrm{a}}$ & $31,2 \mathrm{a}^{\mathrm{b}}$ & $6,7^{c}$ \\
\hline Outono & $227,7^{\mathrm{c}}$ & $131,5^{\mathrm{a}}$ & $702,9^{b}$ & $673,6^{\mathrm{b}}$ & $710,6^{\text {bc }}$ & $33,1^{\mathrm{a}}$ & $42,5^{\mathrm{b}}$ & $547,5^{\mathrm{b}}$ & $126,2^{\mathrm{a}}$ & $36,4^{\mathrm{a}}$ & $5,3^{\mathrm{b}}$ & $44,1^{\mathrm{a}}$ & $34,5^{\mathrm{a}}$ & $11,3^{\mathrm{a}}$ \\
\hline Inverno & $215,0^{\mathrm{c}}$ & $124,2^{\mathrm{a}}$ & $712,6^{\mathrm{ab}}$ & $687,1^{\mathrm{b}}$ & $723,5^{\mathrm{c}}$ & $35,6^{\mathrm{a}}$ & $36,4^{\mathrm{bc}}$ & $551,8^{a b}$ & $135,3^{\mathrm{a}}$ & $33,9^{\mathrm{a}}$ & $12,6^{\mathrm{a}}$ & $42,3^{\mathrm{a}}$ & $28,3^{\mathrm{b}}$ & $7,2^{\mathrm{bc}}$ \\
\hline $\mathrm{CV} \%$ & 14,9 & 11,3 & 2,25 & 1,72 & 1,19 & 15,2 & 15,9 & 3,0 & 8,9 & 11,6 & 20,1 & 18,2 & 12,7 & 16,2 \\
\hline
\end{tabular}

$1-\mathrm{Em} \mathrm{g} \mathrm{kg}^{-1}$ de matéria natural

2 - Em $\mathrm{g} \mathrm{kg}^{-1}$ de matéria seca

Médias seguidas de mesma letra, nas colunas, não diferem pelo teste " $\mathrm{t}$ ", em $5 \%$ de probabilidade de erro. 
Tabela 2 - Quantidades de Matéria Seca (MS), Proteína Bruta (PB), Fibra em Detergente Neutro (FDN), Fibra em Detergente Neutro corrigida para cinzas e proteínas (FDNcp), Carboidratos Totais (CHT), Lignina (Lig), Carboidratos Não Estruturais (CNE), Frações $\mathrm{B}_{2}$ e $\mathrm{C}$ de Carboidratos e Frações $\mathrm{A}, \mathrm{B}_{1}, \mathrm{~B}_{2}, \mathrm{~B}_{3}$ e $\mathrm{C}$ de compostos nitrogenados das gramíneas em uma mesma estação do ano.

\begin{tabular}{|c|c|c|c|c|c|c|c|c|c|c|c|c|c|c|}
\hline \multirow[b]{2}{*}{ Amostra* } & \multirow[b]{2}{*}{$\mathrm{MS}^{1}$} & \multirow[b]{2}{*}{$\mathrm{PB}^{2}$} & \multirow[b]{2}{*}{$\mathrm{FDN}^{2}$} & \multirow[b]{2}{*}{$\mathrm{FDNcp}^{2}$} & \multirow[b]{2}{*}{$\mathrm{CHT}^{2}$} & \multirow[b]{2}{*}{ Lig. $^{2}$} & \multicolumn{3}{|c|}{ Frações de CHT } & \multicolumn{5}{|c|}{ Frações nitrogenadas } \\
\hline & & & & & & & $\mathrm{CNE}^{2}$ & $\mathrm{~B}_{2}{ }^{2}$ & $C^{2}$ & $A^{2}$ & $\mathrm{~B}_{1}{ }^{2}$ & $\mathrm{~B}_{2}^{2}$ & $\mathrm{~B}_{3}{ }^{2}$ & $\mathrm{C}^{2}$ \\
\hline \multicolumn{15}{|c|}{ Primavera } \\
\hline CEC & $181,2^{\mathrm{c}}$ & $73,9^{\mathrm{c}}$ & $756,2^{a}$ & $720,3^{b}$ & $800,8^{a}$ & $55,3^{\mathrm{a}}$ & $80,6^{\mathrm{a}}$ & $571,1^{b}$ & $149,2^{\mathrm{a}}$ & $22,6^{b}$ & $2,6^{\mathrm{b}}$ & $25,7^{\mathrm{a}}$ & $10,3^{\mathrm{c}}$ & $12,7^{\mathrm{a}}$ \\
\hline HEM & $207,3^{\mathrm{b}}$ & $94,3^{\mathrm{a}}$ & $775,5^{\mathrm{a}}$ & $743,7^{\mathrm{a}}$ & $791,2^{\mathrm{a}}$ & $50,4^{\mathrm{a}}$ & $47,5^{b}$ & $635,9^{\mathrm{a}}$ & $107,8^{\mathrm{b}}$ & $31,1^{\mathrm{a}}$ & $0,73^{\mathrm{c}}$ & $26,2^{\mathrm{a}}$ & $23,5^{\mathrm{a}}$ & $12,8^{\mathrm{a}}$ \\
\hline CEP & $253,6^{\mathrm{a}}$ & $92,8^{\mathrm{a}}$ & $726,1^{b}$ & $698,1^{\mathrm{c}}$ & $766,0^{\mathrm{b}}$ & $36,8^{b}$ & $67,9^{\mathrm{a}}$ & $565,5^{b}$ & $132,6^{\mathrm{a}}$ & $27,1^{\mathrm{ab}}$ & $5,6^{\mathrm{a}}$ & $30,5^{\mathrm{a}}$ & $19,3^{b}$ & $10,2^{a}$ \\
\hline \multicolumn{15}{|l|}{ Verão } \\
\hline CEC & $240,9^{b}$ & $38,2^{\mathrm{c}}$ & $811,6^{a}$ & $794,5^{\mathrm{a}}$ & $865,1^{\mathrm{a}}$ & $61,2^{\mathrm{a}}$ & $70,6^{\mathrm{a}}$ & $633,0^{\mathrm{b}}$ & $161,5^{\mathrm{a}}$ & $9,8^{\mathrm{c}}$ & $2,2^{b}$ & $13,8^{\mathrm{b}}$ & $2,5^{\mathrm{c}}$ & $9,8^{\mathrm{a}}$ \\
\hline HEM & $248,6^{\mathrm{b}}$ & $69,8^{\mathrm{b}}$ & $788,9^{a}$ & $775,4^{\mathrm{a}}$ & $839,7^{\mathrm{b}}$ & $44,8^{\mathrm{b}}$ & $64,3^{\mathrm{a}}$ & $678,2^{\mathrm{a}}$ & $97,2^{\mathrm{c}}$ & $21,2^{\mathrm{b}}$ & $1,5^{\mathrm{b}}$ & $20,5^{\mathrm{b}}$ & $14,2^{\mathrm{b}}$ & $12,4^{\mathrm{a}}$ \\
\hline CEP & $282,0^{\mathrm{a}}$ & $117,0^{\mathrm{a}}$ & $746,6^{b}$ & $721,0^{\mathrm{b}}$ & $741,9^{\mathrm{c}}$ & $42,5^{\mathrm{b}}$ & $20,9^{b}$ & $589,1^{\mathrm{c}}$ & $131,9^{b}$ & $34,0^{\mathrm{a}}$ & $4,6^{\mathrm{a}}$ & $40,4^{\mathrm{a}}$ & $31,2^{\mathrm{a}}$ & $6,7^{b}$ \\
\hline \multicolumn{15}{|c|}{ Outono } \\
\hline CEC & $280,4^{\mathrm{a}}$ & $37,2^{\mathrm{c}}$ & $792,9^{\mathrm{a}}$ & $780,4^{\mathrm{a}}$ & $865,9^{\mathrm{a}}$ & $81,3^{\mathrm{a}}$ & $85,5^{\mathrm{a}}$ & $612,1^{\mathrm{b}}$ & $168,3^{\mathrm{a}}$ & $10,6^{\mathrm{c}}$ & $4,1^{\mathrm{a}}$ & $11,1^{\mathrm{c}}$ & $2,2^{\mathrm{c}}$ & $9,1^{\mathrm{a}}$ \\
\hline HEM & $262,0^{\mathrm{a}}$ & $73,2^{b}$ & $796,4^{\mathrm{a}}$ & $772,9^{\mathrm{a}}$ & $814,9^{b}$ & $56,2^{\mathrm{b}}$ & $41,9^{b}$ & $688,9^{\mathrm{a}}$ & $84,0^{\mathrm{c}}$ & $21,6^{\mathrm{b}}$ & $2,2^{\mathrm{b}}$ & $21,7^{\mathrm{b}}$ & $16,8^{\mathrm{b}}$ & $10,9^{\mathrm{a}}$ \\
\hline CEP & $227,7^{b}$ & $131,5^{\mathrm{a}}$ & $702,9^{\mathrm{b}}$ & $673,6^{\mathrm{b}}$ & $710,6^{\mathrm{c}}$ & $33,1^{\mathrm{c}}$ & $42,5^{b}$ & $547,5^{\mathrm{c}}$ & $126,1^{b}$ & $36,4^{\mathrm{a}}$ & $5,3^{\mathrm{a}}$ & $44,1^{\mathrm{a}}$ & $34,5^{\mathrm{a}}$ & $11,3^{\mathrm{a}}$ \\
\hline \multicolumn{15}{|c|}{ Inverno } \\
\hline CEC & $253,7^{\mathrm{a}}$ & $57,2^{\mathrm{c}}$ & $797,9^{\mathrm{a}}$ & $779,8^{a}$ & $814,4^{\mathrm{a}}$ & $66,6^{\mathrm{a}}$ & $34,7^{\mathrm{a}}$ & $602,1^{\mathrm{b}}$ & $177,7^{\mathrm{a}}$ & $18,2^{\mathrm{b}}$ & $8,3^{\mathrm{b}}$ & $13,6^{\mathrm{c}}$ & $5,3^{\mathrm{b}}$ & $11,8^{\mathrm{a}}$ \\
\hline HEM & $230,6^{\mathrm{b}}$ & $99,6^{\mathrm{b}}$ & $789,6^{a}$ & $762,5^{\mathrm{a}}$ & $788,8^{\mathrm{b}}$ & $48,6^{\mathrm{b}}$ & $26,4^{\mathrm{a}}$ & $663,4^{a}$ & $99,1^{\mathrm{c}}$ & $31,7^{\mathrm{a}}$ & $2,4^{\mathrm{c}}$ & $23,8^{\mathrm{b}}$ & $30,4^{\mathrm{a}}$ & $11,3^{\mathrm{a}}$ \\
\hline CEP & $215,0^{\mathrm{c}}$ & $124,2^{\mathrm{a}}$ & $712,6^{b}$ & $687,1^{\mathrm{b}}$ & $723,5^{c}$ & $35,6^{\mathrm{b}}$ & $36,4^{\mathrm{a}}$ & $551,8^{c}$ & $135,3^{b}$ & $33,9^{\mathrm{a}}$ & $12,6^{\mathrm{a}}$ & $42,3^{\mathrm{a}}$ & $28,3^{\mathrm{a}}$ & $7,2^{\mathrm{b}}$ \\
\hline $\mathrm{CV} \%$ & 11,4 & 10,3 & 12,2 & 5,02 & 3,19 & 10,2 & 5,98 & 7,30 & 8,90 & 10,6 & 13,1 & 13,9 & 16,7 & 12,2 \\
\hline
\end{tabular}

${ }^{*} \mathrm{CEC}$ - capim elefante manejado como capineira, HEM - capim hemártria, CEP - capim elefante sob pastejo.

${ }^{1}$ - Em $\mathrm{g} \mathrm{kg}^{-1}$ de matéria natural

2 - Em $\mathrm{g} \mathrm{kg}^{-1}$ de matéria seca

Médias seguidas de mesma letra, nas colunas, não diferem pelo teste “t”, em 5\% de probabilidade de erro.

capineira (CEC). Para o CEP, os menores valores de FDN foram obtidos no outono. Os valores mais baixos de FDN foram os do capim elefante pastejo (Tabela 2). As quantidades de lignina no capim elefante manejado como capineira foram as maiores entre os capins (Tabela 2), provavelmente devido à maior proporção de colmos observados nesta forma de manejo. Tal aspecto confere um menor valor nutritivo, já que a lignina não é digerida e atua reduzindo a digestibilidade potencial da fração fibrosa do alimento (TRAXLER et al., 1998).

Ao longo do ano, o teor de proteína bruta no CEC diminuiu após a primavera, apresentando seu nível mais baixo no outono, época em que foram observados os maiores níveis de lignina na matéria seca (Tabela 1). O capim hemártria teve valores de proteína bruta que variaram de $69,8 \mathrm{~g} \mathrm{~kg}-1$ de MS no verão, a 99,7g kg-1 de MS no inverno (Tabela 1). Estes resultados são similares aos obtidos por GHISI et al. (1995), em oito acessos de capim hemártria analisados em São Paulo. Esta gramínea teve valores de FDN tão altos quanto os encontrados para o capim elefante manejado como capineira. Os valores de lignina do capim hemártria tiveram poucas variações ao longo do ano, sendo o maior valor $(56,2 \mathrm{~g} \mathrm{~kg}-1$ de $\mathrm{MS})$ observado no outono e o menor (44,8g kg-1 de MS), verificado no verão. Excetuando o resultado verificado para o HEM, na primavera, o capim elefante proveniente do sistema de pastejo rotacionado teve os maiores valores de proteína bruta (Tabela 2). Ao longo do ano, neste tipo de manejo, o menor valor $(92,8 \mathrm{~g} \mathrm{~kg}-1 \mathrm{de}$ MS) foi obtido na primavera. Os maiores valores (131,5g kg-1 de MS e 124,2g kg-1 de MS), foram obtidos no outono e no inverno (Tabela 1). Devido à utilização da fertirrigação nos piquetes de capim elefante, a partir do final do verão, é possível que estes níveis maiores estejam relacionados com o aumento da fertilidade da área de pasto, naquelas épocas do ano. $\mathrm{O}$ menor teor de lignina encontrado no CEP (Tabela 1) pode resultar em uma maior digestibilidade dos constituintes da parede celular do capim elefante sob pastejo quando comparado aos teores observados no mesmo capim sendo usado como capineira. A este fato, associa-se uma relação entre os teores de lignina e celulose que variou de 0,16 a 0,22 para o capim elefante manejado como capineira; 0,16 a 0,22 para o capim hemártria e 0,11 a 0,14 para o capim elefante sob pastejo. VAN SOEST (1994) apresenta uma variação na relação 
lignina/celulose para gramíneas tropicais entre $0,11 \mathrm{e}$ 0,24 .

Em todas as estações do ano, a concentração de carboidratos totais foi maior no capim elefante manejado como capineira do que nos outros capins (Tabela 2). O capim hemártria, exceto no período da primavera, teve valores intermediários e, o capim elefante sob pastejo, os menores valores (Tabela 1). Os resultados obtidos estão abaixo do valor médio relatado por ROSTON (1990) para o capim elefante, porém semelhantes aos valores obtidos por CABRAL et al. (2000a), em duas idades de corte para a mesma gramínea. Os valores relativos ao fracionamento dos carboidratos das forrageiras são semelhantes aos encontrados por MALAFAIA et al. (1998) e CABRAL et al. (2000a), para o capim elefante. Os valores obtidos para a fração de carboidratos não estruturais (CNE), estão dentro da amplitude descrita por VAN SOEST (1994) para gramíneas tropicais (2 e 10\% do total de carboidratos) e tiveram variações entre capins e ao longo do ano. Os valores do inverno foram os menores nas três forrageiras, sendo que o capim elefante manejado como capineira teve os maiores valores relativos à fração CNE nas outras estações do ano. A porção de carboidratos fibrosos (FDNcp) foi maior no verão para os três capins, e menor na primavera para os capins elefante manejado como capineira e hemártria (Tabela 1).

Dentre as forrageiras, o capim elefante sob pastejo foi o que teve os menores valores médios de FDNcp. Ao longo do ano, a variação na fração B2 de carboidratos dos capins foi pequena, sendo os maiores valores obtidos no verão, e os menores na primavera para os capins elefante manejado como capineira e hemártria. $\mathrm{O}$ capim hemártria forneceu as maiores quantidades de carboidratos oriundos da fração B2, em todas as estações do ano, e o capim elefante sob pastejo, forneceu as menores quantidades (Tabela 2). Constatou-se no capim elefante manejado como capineira, um aumento da fração $\mathrm{C}$ no período da seca (outono e inverno) relativamente ao período da primavera e do verão (Tabela 2 ). No capim elefante sob pastejo, os valores da fração $\mathrm{C}$ não tiveram diferenças significativas, embora os valores desta fração, exceto nos meses da primavera, ficaram sempre abaixo dos obtidos com o mesmo capim em sistema de capineira (Tabela 2).

O capim hemártria teve os maiores valores da fração B2, e os menores valores da fração C quando comparado ao capim elefante manejado como capineira e ao capim elefante sob pastejo, durante todo o ano (Tabela 2). Embora tenha havido uma pequena variação na fração $\mathrm{C}$ do capim hemártria durante as estações do ano, esta não foi significativa, e os valores obtidos foram inferiores aos verificados no capim elefante em quaisquer tipos de sistema de utilização e em qualquer época do ano (Tabela 2). O maior valor para a fração C no capim hemártria foi encontrado ao longo dos meses de primavera. Estas diferenças tendem a ser representativas quando comparadas as duas espécies estudadas, uma vez que a fração C está relacionada a uma menor digestibilidade dos carboidratos (MALAFAIA et al., 1998).

Os resultados encontrados para as frações nitrogenadas dos capins estudados tiveram variações entre as estações do ano e também entre as espécies e práticas de manejo. Os valores para a fração A foram superiores aos encontrados por MALAFAIA et al. (1998), VAN DER MADE et al. (1998) e por LIMA et al. (1999), em todas as amostras analisadas. Esta fração, correspondente ao nitrogênio não protéico, possui degradação rápida no rúmen. Nos capins elefante e hemártria, foram identificadas alterações da fração ao longo do ano, tanto entre as estações quanto entre espécies (Tabelas 1 e 2). Nos meses de inverno e na primavera, o capim elefante manejado como capineira e a hemártria apresentaram os mais altos valores da fração A, e os menores valores no verão e no outono. No capim elefante sob pastejo, apenas na primavera ocorreu um decréscimo da fração $\mathrm{A}$, em relação às outras estações do ano (Tabela 2). Na maioria das estações do ano, o capim elefante sob pastejo teve as maiores frações de nitrogênio não protéico, não diferindo, entretanto, do capim hemártria nos períodos de inverno e primavera. Para o capim elefante manejado como capineira, os valores obtidos durante o ano, foram inferiores aos dos capins elefante sob pastejo e hemártria. A fração de proteínas de rápida degradação (B1) variou de $0,73 \mathrm{~g} \mathrm{~kg}-1$ de MS para o capim hemártria, no verão, a 12,6g kg-1 de MS para o capim elefante sob pastejo no inverno. Esta amplitude está dentro da variação obtida por outros autores (LANNA et al., 1996; MALAFAIA et al., 1998; VAN DER MADE et al., 1998; CABRAL et al., 2000b) com esta e outras forrageiras tropicais. A quantidade da fração B1 do capim elefante manejado como capineira foi muito superior nos meses de outono e inverno, quando comparada com os meses de primavera e verão; porém, a contribuição final de nutrientes por essa fração é muito pequena (Tabela 1 ).

No capim hemártria, a contribuição da fração B1 variou de 1,12g kg-1 de MS (média de primavera e verão) a 2,3g kg-1 de MS (média do outono e inverno). No capim elefante sob pastejo a variação de $4,6 \mathrm{~g} \mathrm{~kg}-1$ de MS (verão) até 12,6g kg-1 MS (inverno) de proteína solúvel por $\mathrm{kg}$ de MS. Entretanto, estes valores 
correspondem a menos de $10 \%$ do total de proteína contida em um kg de MS. Não obstante, o aumento da fração B1 nos meses de inverno do capim elefante manejado como capineira e do capim elefante sob pastejo, contribuíram para uma diferenciação destes das demais amostras relativamente à fração solúvel dos compostos nitrogenados ingeridos em cada kg de MS. Contudo, nota-se que este aumento da fração B1, observado no período da seca no capim elefante manejado como capineira, ocorreu sem que houvesse uma diminuição relativa da fração $\mathrm{C}$, enquanto, no caso do capim elefante sob pastejo, a fração $C$, correspondente à fração nitrogenada indigestível, teve valores reduzidos quando foi observado o aumento da fração B1.

O capim elefante sob pastejo, em todas as estações, teve os maiores valores da fração B1 (Tabela 1). A fração de compostos nitrogenados formada por proteínas com taxas intermediárias de degradação no rúmen (fração B2) para todas as amostras de capim elefante, foi menor do que os valores encontrados por LANNA et al. (1996), MALAFAIA et al. (1998) e VAN DER MADE et al. (1998). CABRAL et al. (2000b), encontraram valores de 43,1 e 23,4g kg-1 de MS para a fração B2 do capim tifton com 30 e $50 \mathrm{~cm}$ de altura respectivamente e, MALAFAIA et al. (1998), 36,9g kg-1 de MS para aquela fração do mesmo capim com cerca de 60 dias de idade. Neste estudo, o capim elefante, nas duas formas de manejo, apresentou uma variação do valor da fração B2 na época da primavera significativamente menor do que nas outras estações. No capim hemártria, os valores da fração B2 ao longo do ano não diferiram entre si .

As quantidades médias de proteínas provenientes da fração B2 foram maiores no capim elefante sob pastejo durante todo o ano, exceto na primavera. LIMA et al. (1999) salientam que a quantificação do NIDN é importante para se compreender o fracionamento do nitrogênio em gramíneas tropicais, pois parte da proteína que está associada à FDN (fração B3) é potencialmente metabolizável nos intestinos. Os autores, analisando espécies forrageiras, entre elas o capim hemártria, concluíram que aproximadamente $40 \%$ do nitrogênio das gramíneas estava associado à FDN (NIDN), tendo sido obtido o valor de $403 \mathrm{~g} \mathrm{~kg}-1$ de $\mathrm{N}$ total para aquela espécie, com 19,1g kg-1 de MS relativos à fração B3. $\mathrm{O}$ valor médio obtido para o capim hemártria no presente trabalho, foi de $391 \mathrm{~g}$ de NIDN por kg de $\mathrm{N}$ total, com uma variação significativa da fração B3 ao longo do ano; maiores valores no inverno, intermediário na primavera, e menores no verão e outono. Os valores da fração B3 do capim elefante, tanto como capineira quanto como pastejo rotacionado variaram entre as estações do ano. O capim elefante manejado como capineira apresentou seu valor mais alto na primavera, não tendo diferenças nas outras estações. Já o capim elefante sob pastejo mostrou seu valor mais baixo na primavera e valores mais altos no verão e no outono.

Os valores relativos ao capim elefante sob pastejo são similares aos encontrados por MALAFAIA et al. (1998), para o capim elefante com aproximadamente 60 dias de rebrota, e os valores dos meses de verão, outono e inverno da fração B3 do capim elefante manejado como capineira, assemelhamse com aqueles relatados por VAN DER MADE et al. (1998) analisando o mesmo capim em fase de floração. Desta maneira, os resultados obtidos servem para evidenciar que há uma relação entre a idade de corte e outras práticas de manejo do capim elefante e sua concentração em proteínas potencialmente degradáveis nos intestinos. As diferenças entre as épocas do ano, entre espécie e dentro da mesma espécie, contrastam e evidenciam as variações que podem ocorrer em função do manejo da forrageira, principalmente quando é enfocada a participação percentual da fração $\mathrm{C}$ no total da compostos nitrogenados da forrageira. O capim elefante sob pastejo teve uma maior concentração de proteínas ligadas à lignina no período de primavera e outono, e uma concentração menor nos meses de verão e inverno. Para o capim hemártria e o capim elefante manejado como capineira, os valores da fração $C$ não diferiram entre si ao longo do ano. As diferenças observadas neste estudo alcançam maior expressão quando analisadas como valores percentuais da fração $\mathrm{C}$ em relação ao total de compostos nitrogenados ingeridos: 17,1 a $25,7 \%$ no capim elefante manejado como capineira; 11,4 a 17,8\% no capim hemártria; e 5,7 a $11,0 \%$ no capim elefante sob pastejo, evidenciando uma maior digestibilidade da proteína do capim elefante quando o mesmo é explorado em pastejo rotacionado do que quando utilizado para corte em capineira, particularmente nas condições locais de manejo conduzidas neste estudo, no qual o corte da capineira não obedecia a qualquer planejamento, enquanto o pastoreio dos piquetes, além de seguir uma estratégia de utilização, ainda teve a adoção de um sistema de ferti-irrigação, o que pode ter contribuído para os melhores valores obtidos com este sistema.

Os valores da fração $\mathrm{C}$ do capim hemártria estiveram acima daqueles encontrados por LIMA et al. (1999); porém, aqueles autores analisaram plantas em intervalos de rebrota de 4,6 e 8 semanas. No 
presente trabalho, apesar da coleta mensal das amostras, o manejo empregado na área era o de pastejo contínuo e posteriormente, diferimento da área de pastagem.

É importante salientar que o capim elefante manejado como capineira, de acordo com a rotina dos produtores locais, teve os menores valores de proteína bruta e os maiores valores de indisponibilidade desta proteína (fração C), enquanto o mesmo capim, manejado sob pastejo rotacionado, fornece maior quantidade de proteína para o animal, bem como uma menor concentração de proteína indigerível.

\section{CONCLUSÕES}

O capim elefante, utilizado como forrageira para corte diário, possui o menor valor nutritivo, especialmente com redução na quantidade de proteína bruta e aumento das quantidades de lignina e fração C de carboidratos.

O capim elefante manejado para pastejo rotacionado produz a maior quantidade de proteína bruta e as menores quantidades de proteína indigerível e lignina.

O capim hemártria proporciona um bom valor nutritivo nos períodos de seca, destacando-se como o capim que teve as menores frações indigeríveis de carboidratos.

\section{REFERÊNCIAS BIBLIOGRÁFICAS}

ANDRADE, J.B. et al. Composição bromatológica da forragem de Pennisetum purpureum Schum. Cv. Guaçuí, prensada ou não em moenda de cana de açúcar. Boletim da Indústria Animal, v.42, n.1, p.63-66, 1995.

ANDRADE, I.F.; GOMIDE, J.A. Curva de crescimento e valor nutritivo do capim-elefante (Pennisetum purpureum, Schum.) A-146 Taiwan. Revista da Sociedade Brasileira de Zootecnia, v.1, n.1, p.41-58, 1972

ASSOCIATION OF OFFICIAL ANALYTICAL CHEMISTS (AOAC). Official methods of analysis. 15.ed. Arlington: 1990. V.1, 1117p.

CABRAL, L.S. et al. Frações de carboidratos de alimentos volumosos e suas taxas de degradação estimadas pela técnica de produção de gás. Revista Brasileira de Zootecnia, v.29, n.6, p.2087-2099, 2000a.

CABRAL, L.S. et al. Frações protéicas de alimentos tropicais e suas taxas de digestão estimadas pela incubação com proteases ruminais. Revista Brasileira de Zootecnia, v.29, n.3, p.880888,2000 b.

CARVAlHO, D.D., GONÇALEZ, D.A., GHISI, O.A.A. Avaliação agronômica de sete acessos de Hemartria altíssima em Pindamonhagaba, SP. Revista da Sociedade Brasileira de Zootecnia, v.25, n.5, p.825-835, 1996.
GHISI, O.M.A.A.; ALMEIDA, A.R.P.; CARVALHO, D.D. Avaliação agronômica de oito acessos de Hemartria sob corte e pastejo. Boletim da Indústria Animal, v.52, n.2, p.147$152,1995$.

LANNA, D.P.D. et al. Utilização da metodologia de análises de alimentos do CNCPS e do sistema de produção de gás In Vitro na estimativa dado valor nutricional do capim elefante. In: REUNIÃO ANUAL DA SOCIEDADE BRASILEIRA DE ZOOTECNIA, 1996, Fortaleza, CE. Anais... Fortaleza : SBZ, 1996. p.289-291.

LIMA, G.F. et al. Concentração e fracionamento do nitrogênio em gramíneas forrageiras tropicais e subtropicais. In: REUNIÃO ANUAL DA SOCIEDADE BRASILEIRA DE ZOOTECNIA, 1999, Botucatu, SP. Anais... Botucatu : SBZ, 1999. FOR-074.

MALAFAIA, P.A.M.; VIEIRA, R.A.M. Técnicas de determinação e avaliação dos compostos nitrogenados em alimentos para ruminantes. In: SIMPÓSIO INTERNACIONAL DE DIGESTIBILIDADE EM RUMINANTES, 1997, Lavras, MG. Anais... Lavras : FAEPE, 1997. p.29-54

MALAFAIA, P.A.M. et al. Determinação das frações que constituem os carboidratos totais e da cinética ruminal da fibra em detergente neutro de alguns alimentos para ruminantes. Revista Brasileira de Zootecnia, v.27, n.4, p.790-796, 1998

MERTENS, D.R. Using fiber and carbohydrate analisys to formulate dairy rations. In: INTERNATIONAL CONFERENCE WITH DAIRY AND FORAGE INDUSTRIES, 1996, Madison, WI, US Dairy Forage and Research Center. p. 81-92.

MILFORD, R.; MINSON, D.J. Intake of tropical pastures species. In: CONGRESSO INTERNACIONAL DE PASTAGENS, 1966, São Paulo. Anais... São Paulo, n.i., 1966. p.815-822.

PEDREIRA, J.V.S. Crescimento estacional dos capins elefante Napier e Guatemala. Boletim da Indústria Animal, v.33, n.2, p.233-242, 1976.

ROSTON, A.J. Alimentos para ruminantes: composição bromatológica, valor nutritivo, desempenho animal. Jaboticabal. 1990. 121f. Tese (Doutorado em Zootecnia)UNESP.

TRAXLER, M.J. et al. Predicting forage indigestible NDF from lignin concentration. Journal of Animal Science, v.76, n.5, p.1469-1480, 1998.

VAN DER MADE, I.E. et al. Produção de gás oriunda da MS e da FDN da alfafa e do capim elefante. In: REUNIÃO ANUAL DA SOCIEDADE BRASILEIRA DE ZOOTECNIA,1998, Fortaleza, CE. Anais... Botucatu : SBZ, 1998. p.56-57.

VAN SOEST, P.J.; ROBERTSON, J.B.; LEWIS, B.A. Methods for dietary fiber, neutral detergent fiber, and nonstarch polysaccharides in relation to animal nutrition. Journal of Dairy Science, v.74, n.5, p.3583-3597, 1991.

VAN SOEST, P.J. Nutritional ecology of the ruminant. Ithaca : Cornell University, 1994. 476p. 